\title{
MATERIALES VISIGODOS DE LA EXCAVACIÓN DE SAN PEDRO MÁRTIR (TOLEDO)
}

\author{
RAFAel BARRoso CABRERA \\ JORGE MORIN DE PABLOS
}

\section{Resumen}

Los tres nuevos ejemplares escultóricos descubiertos en las excavaciones de San Pedro Mártir vienen a incrementar el corpus de esculturas hispanovisigodas de la ciudad de Toledo. El hallazgo de un nuevo ejemplar de nicho resulta además significativo no solo por la singularidad de su decoración, sino porque permite establecer algunas hipótesis sobre su pertenencia a un complejo bautismal cercano a la sede catedralicia.

Palabras clave: San Pedro Martir. Escultura. Visigodo. Nicbos.

\section{Abstract}

The three new sculptures discovered at San Pedro Martir archaeological dig increase the corpus of Hispanic-Visigothic sculptures of Toledo. Besides, the discovering of a new type of niche is significant not only because of the singularity of its decoration, but also because it enables us to establish some hypotheses about its beionging to a baptismal complex near the cathedral see.

Key words: San Pedro Märtir, sculpture, Visigotbic, niche.

En el transcurso de una intervención arqueológica dirigida por el profesor D. Fernando Valdés en el convento de San Pedro Mártir de Toledo, previa a la rehabilitación del complejo conventual -el más extenso de la trama urbana-, salió a la luz un pe- 
queño lote de esculturas de época visigoda. La importancia de alguna de estas piezas justifica un estudio detallado de las mismas más allá de la simple descripción de los materiales.

\section{NICHO}

\section{Dimensiones}

Longitud: $0,19 \mathrm{~m}$; Altura: $0,43 \mathrm{~m}$; Profundidad: $0,23 \mathrm{~m}$.

\section{Descripción}

Nicho realizado en mármol blanco, fragmentado en la actualidad. Se conserva de forma fragmentaria, habiendo perdido parte del motivo central, la venera que lo cobijaba y la totalidad de la parte izquierda de la escultura. Por lo demás, el estado de conservación es bueno. Los laterales y el fondo de este ejemplar se han trabajado con el puntero, pero sin cincelar. La talla de la hornacina es una combinación de la técnica de rehundido y bisel, con predominio de esta última, de forma que la decoración resalta sobre el fondo del nicho (láminas 1 y II $\mathrm{a}-\mathrm{b}$ ).

\section{Decoración}

Nicho decorado con un crismón invertido de brazos patados con terminaciones cóncavas, inscrito en un doble círculo. De este crismón pende una omega $(\omega)$ sostenida con cadenillas y cobijado por una venera de gallones de la que sólo conserva su arranque. En la parte inferior se aprecia parte de un motivo esquemático, probablemente vegetal. En el lateral derecho se ha tallado una columna con un gran plinto cúbico, listel, escocia y toro, que flanquea la decoración por este lado. El fuste es sogueado y el capitel, muy simple, presenta collarino y dos volutas sueltas. Por último, entre la columna y el motivo central, se dispone una decoración de círculos tangentes formando rosetas tetrapétalas con boton central.

\section{Estudio}

En la serie de nichos y placas-nicho visigodos, el motivo situado en el centro del edículo constituye el elemento principal de la decoración. En el caso que nos ocupa, se trata de un crismón con las letras apocalipticas invertidas $(\omega-\alpha)$.

El motivo del crismón es, junto con la cruz, uno de los símbolos cristológicos fundamentales del arte cristiano. No sólo constituye el anagrama de Cristo, sino que en sí 


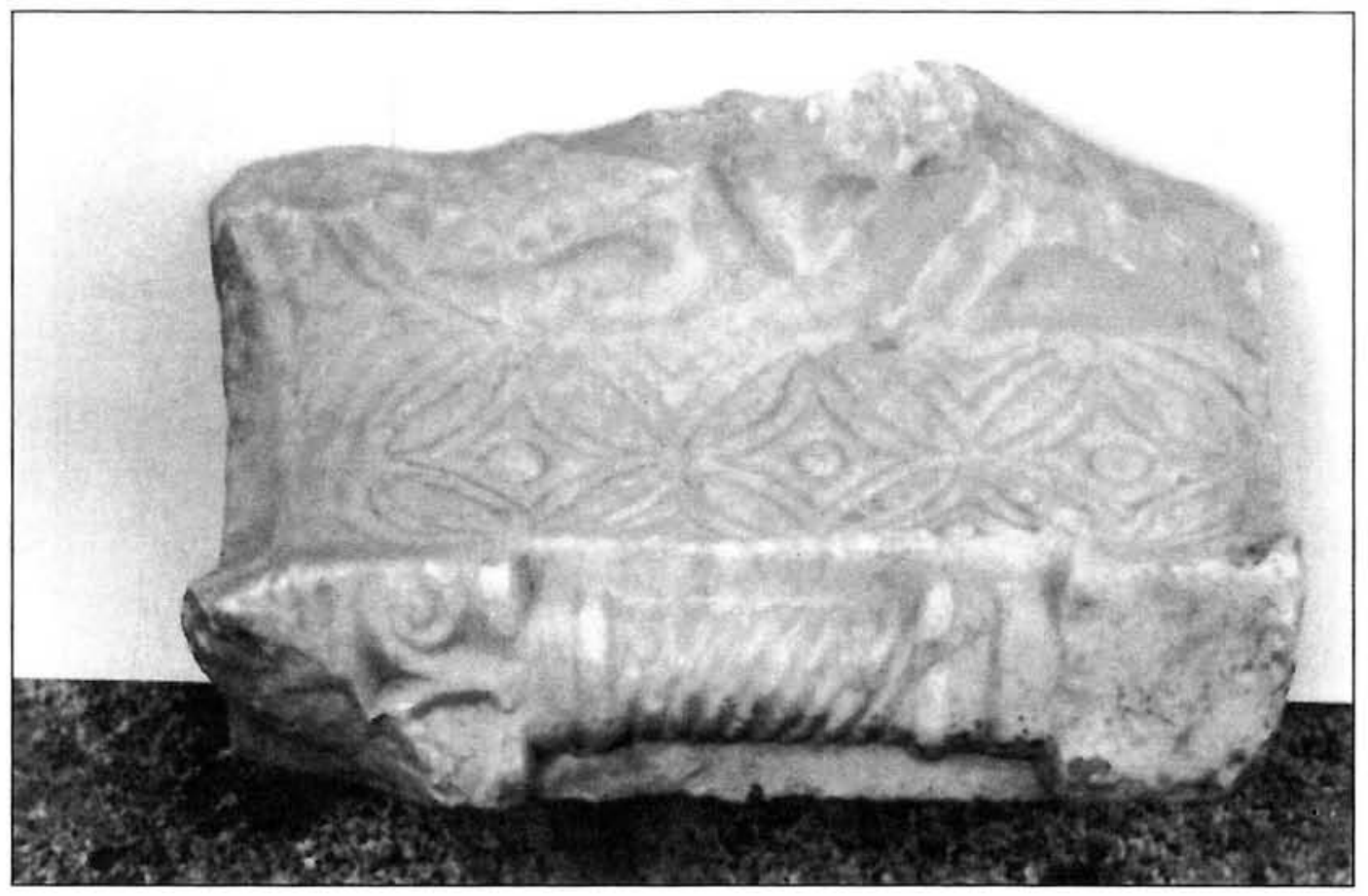

Lámina I. Nicho. Convento de San Pedro Mártir (Toledo)

viene a manifiestarle como principio y fin de la creación según la narración apocalíptica. Lógicamente se trata de uno de los símbolos que aparece representado con mayor asiduidad en la serie de los nichos. Su aparición es aquí notable si lo comparamos con otro tipo de piezas, empleándose para ello una tipología muy definida que con muy pocas variantes se difundirá descle Mérida hacia otros centros artísticos como Toledo y Córdoba. La presencia de los crismones en la capital lusitana es muy significativa, tanto descle el punto de vista cuantitativo como por su extraordinaria calidad, dando como resultado la configuración de un tipo propio a partir de los modelos bizantinos y ravenáticos que es el que influirá en las posteriores representaciones toledanas.

Los crismones aparecen esculpidos en piezas muy concretas (lel mobiliario litúrgico emeritense como son los nichos y canceles. Fl motivo suele encontrarse resaltado mediante una venera, o bien bajo arco o encerrado en clípeo, siempre significado solbre el resto de la decoración que le acompana. De hecho, su aparición queda casi exclusivamente circunscrita a piezas de primer orden, en elementos cuya situación es privilegiada dentro (lel templo, bien dentro del sanctuarium o justo en sus inmediaciones, como en los canceles que cierran el santuario.

Estas oloservaciones fueron notadas ya por Schlunk y Hauschild, quienes formularon la sugestiva hipótesis del sentido trascendente que pudo adquirir la talla reiterada de los grandes crismones que serían interpretados en esta época como símbolo del triunfo 


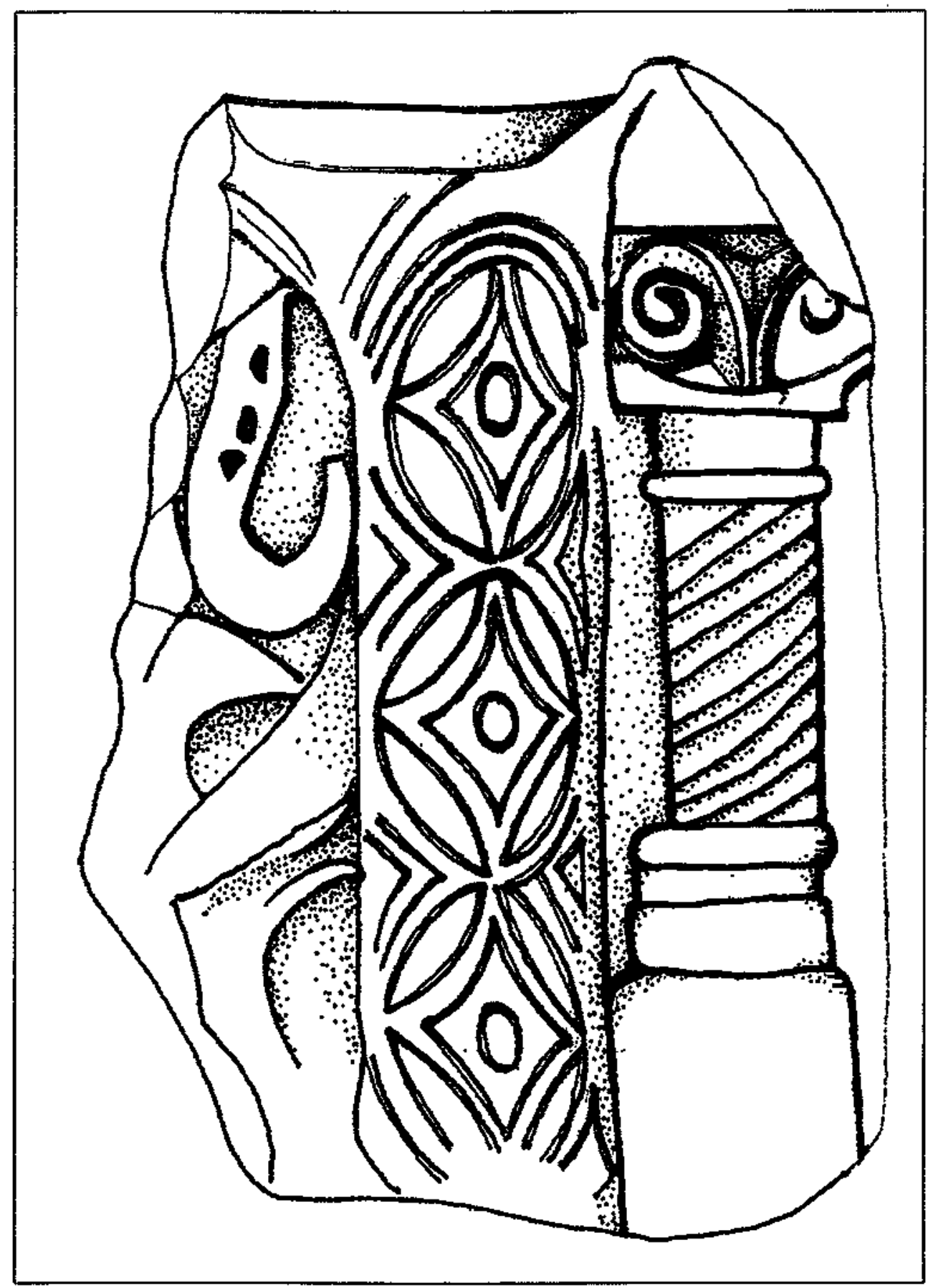

Lamina IIa. Friso. Convento de San Pedro Mártir (Toledo) 


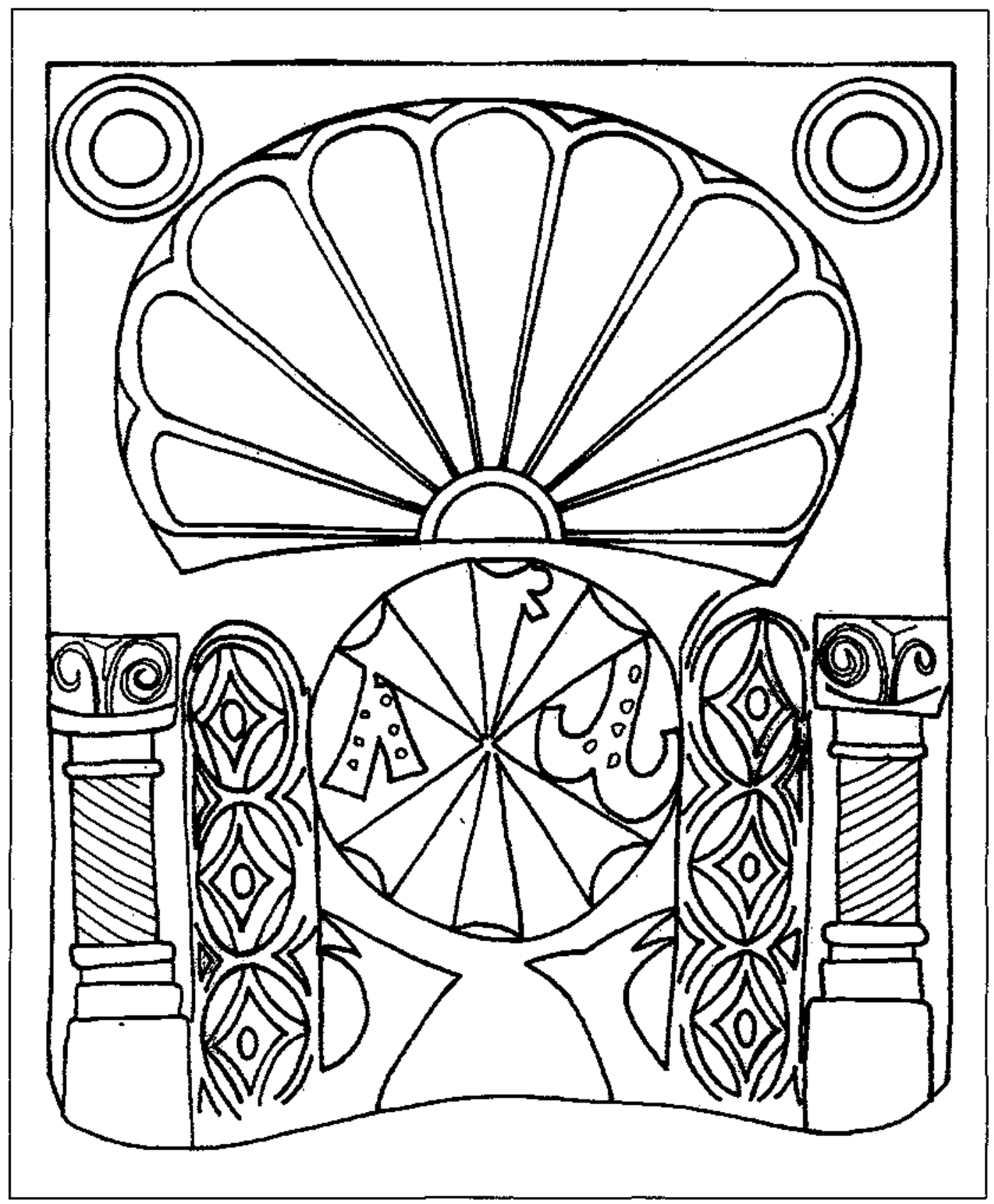

Ldmina IIb. Reconstrucción 
de la fe católica sobre el arrianismo (SCHLUNK-HAuSCHILD, 1978, 68-69). Esta opinión es compartida también por Cruz Villalón, quien resalta además que es precisamente en Mérida y Toledo - las ciudades protagonistas de importantes acontecimientos relacionados con la disputa arriana- donde se encuentran repetidos con mayor frecuencia estos motivos cristológicos (CRUZ Vilualón, 1985, 69). A nuestro juicio, la intencionalidad ideológica se muestra evidente en la representación del monograma en series triples, simbolizando el misterio trinitario, lo que encuentra su paralelo en algunas figuraciones del arte ostrogodo contemporáneo (GIORDANI, 1978, 229-263; FERRUA, 1991).

El tipo de crismón representado en nuestro nicho es el habitual en la serie. Se trata de un crismón con los brazos patados y extremidades cóncavas que parten de un disco central. El stipes o brazo vertical suele ser de mayor grosor que los brazos de la cbi. De estos últimos colgarian mediante cadenillas las letras apocalípticas que, como se ha dicho ya, presentan además la particularidad de que encontrarse invertidas. La rbo no se ha conservado, pero suele expresarse por un pequeño circulito acompañado por un apéndice oblicuo que se ensancha al final, aunque en la placa-nicho de la Vega Baja - la única pieza toledana en la que aparece esta letra - la encontramos ya latinizada (FrANCO MATA, 1982, 289-298).

El crismón del nicho de San Pedro Mártir corresponde al tipo 1 de la clasificación de Cruz Villalón. Según esta autora, el tipo presenta claras raíces bizantinas puestas de manifiesto en la conformación ensanchada de los brazos, el remate cóncavo de éstos y la decoración imitando la técnica de engastado de piedras preciosas típica de la orfebrería tardorromana (CRUZ VILLALÓN, 1985, 287-292). Todos ellos son rasgos propios del arte bizantino que se descubren también en el arte de la Rávena de la sexta centuria. Sin embargo, los paralelos más estrechos para este tipo de crismón se encuentran en algunas piezas de orfebreria oriental de la primera mitad del siglo VI, como ponen de manifiesto la patena del obispo Paternus (BANK, 1977, 281, fig. 66), un cáliz procedente de Siria (WEITZMANN, 1978-79, 608, n. ${ }^{\circ}$ 543) y los colgantes de un collar del Museo del Ermitage (BANK, 1977, 286, fig. 94). Este prototipo debió llegar a Mérida a través del comercio directo con Oriente o a partir del África bizantina. Desde allí se difundió hacia Toledo, donde el motivo sufrió algunas variaciones que tienden hacia la simplificación formal y la esquematización.

Un aspecto importante en el nicho de San Pedro Mártir al que ya hemos hecho referencia es que presenta alteradas las letras apocalípticas, de forma que la omega (la única conservada) aparece en el lado derecho del crismón. La razón de este cambio obedece a cuestiones simbólicas como puso de manifiesto $M$. Guarducci en sus estudios sobre grabados paleocristianos (GUARDuccl, 1958, 1, 45ss y 1959, 94), y no a un error del artesano como pretenden algunos autores (CERRLLO M. DE CÁCERES, 1972-73, 261-268; 1979, 199-209). El sentido de estas representaciones parece haber sido el de significar el paso de la muerte a la vida, entendiendo como tal el paso de la vida terrena a la vida espiritual proporcionada por la fe. De ahí que generalmente la inversión de las letras aparezca dentro de un contexto bautismal (como símbolo de la recepción a la vida de la gracia) o puramente escatológico y funerario. 
Obviamente la inversión iba ligada también a la idea de la muerte y resurrección de Cristo proclamada en el sacrificio de la misa. No se olvide que estos nichos debieron coronar la decoración de las iglesias, convirtiéndose en el centro simbólico de su iconografía. No obstante, parece más apropiado ver en esta alteración una intencionalidad simbólica de tipo bautismal, quizás ligada a las ceremonias litúrgicas que seguían a la recepción del sacramento (aceptación del símbolo y administración de la eucaristía), máxime teniendo en cuenta la vinculación mística que existe entre el bautismo y la eucaristía, y de ambos con el misterio de la muerte-resurrección de Cristo. En este sentido, la lectura de la inversión de las letras alfa y omega vendría a simbolizar el paso de la muerte (esto es, de la vida mundana) a la vida espiritual que proporciona el ingreso del neófito en la Iglesia.

En la Península Ibérica encontramos crismones $\omega-\mathrm{A}$ en un número abundante de piezas paleocristianas (cerámicas, mosaicos, esculturas, etc.), si bien para la época que nos ocupa no suele ser un caso habitual. Sin embargo, contamos con importantes ejemplos en distintos relieves escultóricos: el relieve de Montánchez (Cáceres) (CERRILLO M. DE CÁCERES, 1972-73 y 1979; BARROSO-MORIN, 1995), una placa procedente de Mérida (CERRILIO M. DE CÁCERES, 1974, 444) y una pila bautismal de Mérida (CRUZ Villalón, 1985, 100, fig. 198). En el arte románico español es habitual encontrar crismones con inversión de las letras apocalípticas dentro de contextos funerarios (por la asociación de la muerte del fiel a la idea de la eucaristía) o bautismales, generalmente en pilas bautismales y puertas de difuntos (ALONSO SÁNCHEZ, 1983, 297-302 y 1989, 1131-1142).

Bajo este motivo central, el nicho de San Pedro Mártir presenta aún restos de decoración de difícil lectura dado lo fragmentario de su estado. Parece tratarse de un motivo vegetal esquematizado semejante al que encontramos en el gran nicho de Mérida (lámina III) y que ha sido interpretado como los dos cipreses que se inclinan ante la divinidad según una narración del profeta Ezequiel (Ez. XXXVI,35 y XIVII,12) (HOPPE, 1987, 33). Parece más lógico ver en ellos, dadas sus características formales, los dos olivos de la visión del Templo espiritual del profeta Zacarias (Zac. IV,1-3; 11-14). No serían estos los únicos elementos del gran nicho de Mérida relacionables con esta profecía: los dos candeleros que flanquean la imagen del crismón hacen referencia al candelero de oro que está en el santuario del Templo y que simboliza los ojos del Señor (Zac. IV,10). Las representaciones vegetales de la placa de San Pedro Mártir parecen remitir de nuevo a estos dos olivos.

El tema de los dos olivos y los dos candeleros que alumbran delante del trono de Dios aparece retomado en un pasaje famoso del Apocalipsis de San Juan (Apoc. XI,3-4). Estos dos candeleros y olivos tienen una dificil identificación, pues la tradición cristiana altomedieval varía en su atribución entre Moisés y Elias o Elías y Henoc, incluso entre Elías y Jeremías. En cualquier caso, el cristianismo ha contemplado en ellos un símbolo de la Ley y el Evangelio: "Esto, en sentido literal, se refiere a Elias y al que ba de venir con él; pero abora refirámoslo en sentido espiritual a los dos Testamentos, que son la Ley y el Evangelio. Estos son los dos olivos y los dos candeleros. Tal candelero que se describe por Moisés como teniendo siete brazos, es la septiforme Iglesia llena del Espiritu. Y los dos olivos son la Ley y el Evangelio." (Beato, Sum. dic. 4). Una interpretación similar había 
sido propuesta ya por el obispo Apringio de Beja dos siglos antes: "Dice que ellos (Elías y. Jeremías) son los dos candeleros, los dos olivos: lo bizo notar para que, si al leerlo en otro texto no lo entendiste, lo entiendas aquí; pues está escrito en Zacarias, uno de los doce profetas: 'ellos son los dos olivos y los dos candeleros que están ante la presencia del Señor de la tierra', es decir, están en el Paraíso..." (Aprin. In Apoc. XI,4).

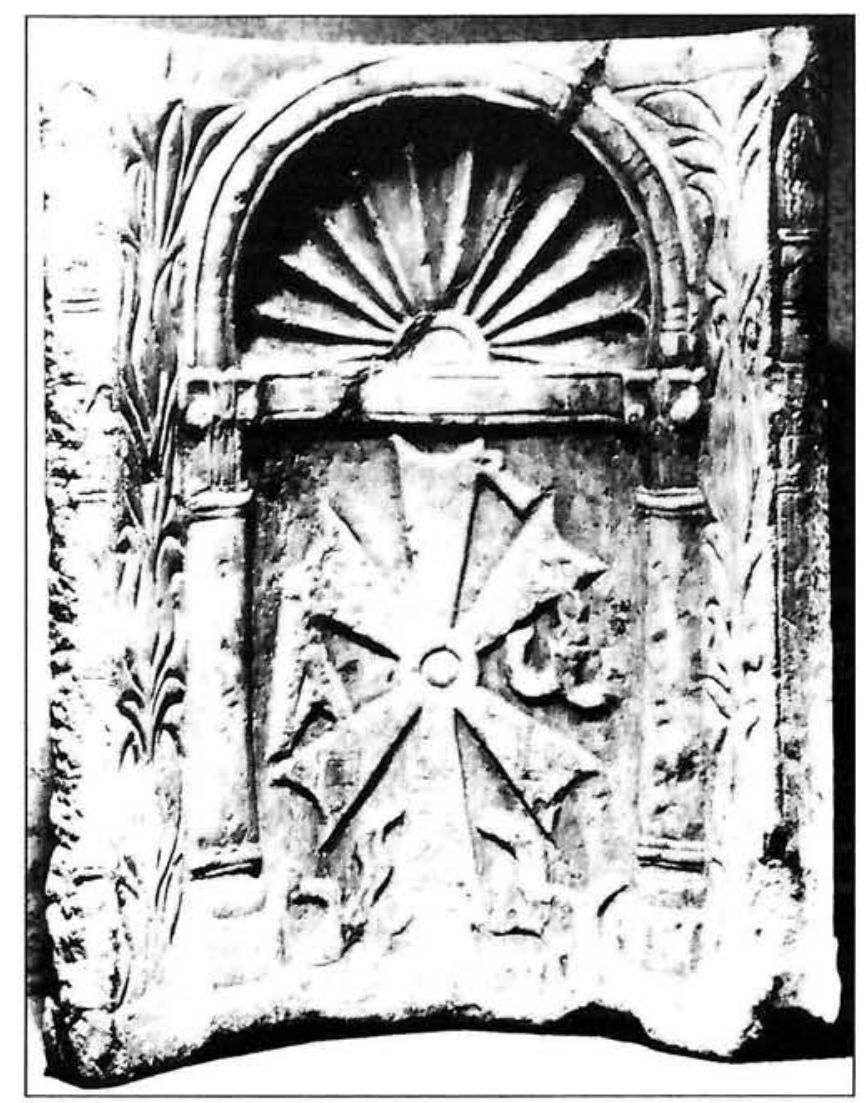

Lámina III. Gran nicho de Mérida. Museo Arqueológico de Méricla. (Fotografía del Instituto Arqueológico Alemán cle Madrid)

Esta interpretación parece corroborarse a través de su comparación con otras piezas toledanas. Los nichos de San Andrés (lámina IV) y Santo Tomé (lámina V), por ejemplo, presentan dos motivos vegetales esquematizados en trifolia flanqueando un motivo central cristológico. A pesar de su esquematismo, estos elementos vegetales difícilmente pueden ser interpretados como cipreses, que en el arte siempre presentan una forma alargada con tendencia triangular bien reconocible como se ve, por ejemplo, en el bloque-capitel de entrada al ábside de la iglesia portuguesa de São Gião (Nazaré) (Almeid)ABorges, 1965 , 405-407, foto 2) o en el pluteus procedente de la iglesia de Santa María 
del Camí (La Garriga, Gerona) (PAl.ot., 1950, 8). Por el contrario, en los nichos toledanos la esquematización del motivo original ha conducido hacia una forma cuadrangular. Fsta evolución permite adivinar para el modelo original un motivo vegetal semejante a los que decoran la placa de San Pedro Mártir y del gran nicho de Mérida.

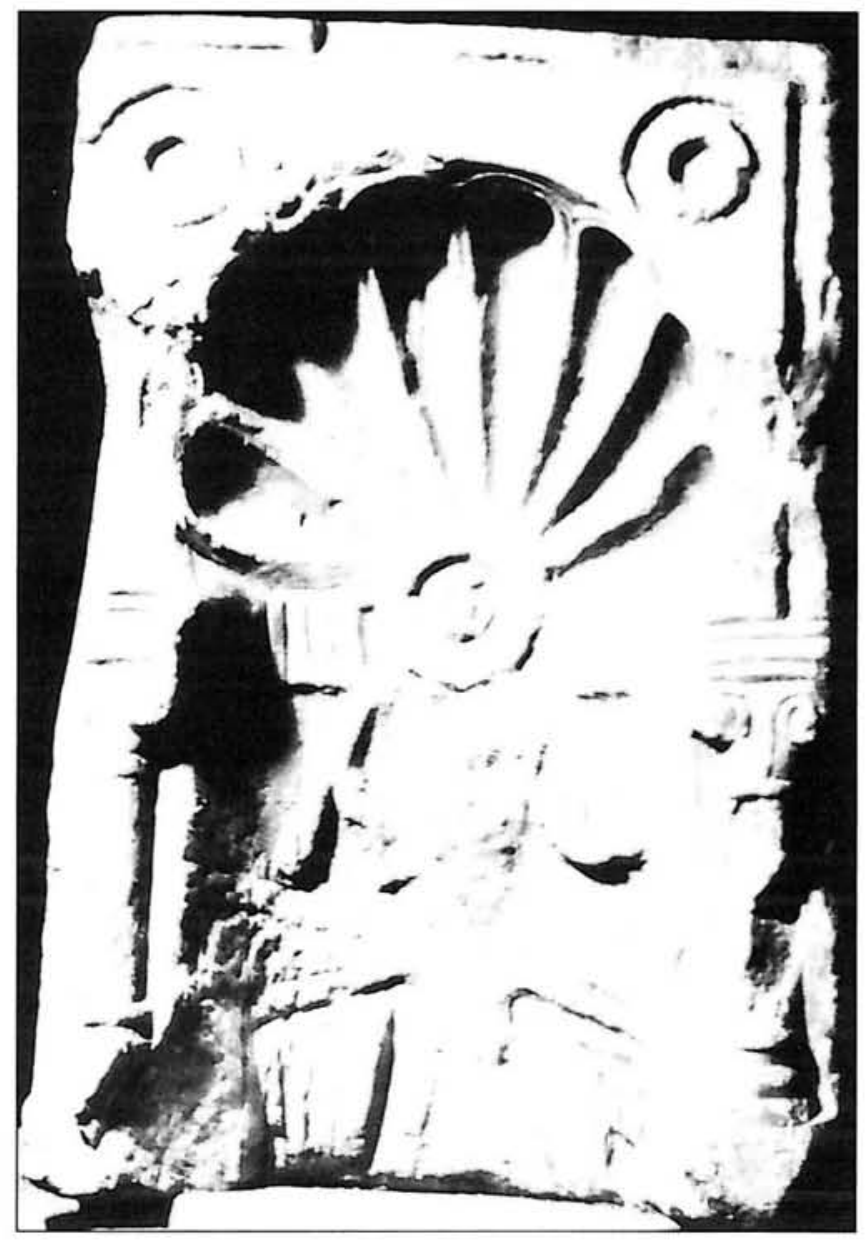

Lämina IV. Nicho de San Andrés (Toledo). Museo de Ios concilios

El prototipo de esta serie de nichos toledanos parece encontrarse precisamente en el gran nicho de Méricla (lámina III) en el cual se inspirarían todos ellos manteniendo las líneas esenciales, pero con la decoración paulatinamente degenerada. Es posible, con todo, seguir una cierta evolución en el clesarrollo de estas piezas. El nicho de Santo Tomé (lámina V), por ejemplo, presenta mayores afiniclades formales con el de Méricla, además 
de una talla más preciosista. Fste nicho o uno similar como el estudiaclo por Ángela Franco (1982, 291-298) formaría el modelo para el resto de la serie toleclana, caracterizada por la simplificación de los elementos decorativos: desaparición de la decoración vegetal lateral o sustitución por motivos más simples de tipo geométrico; esquematización del crismón o transformación de éste en una cruz patada, etc.

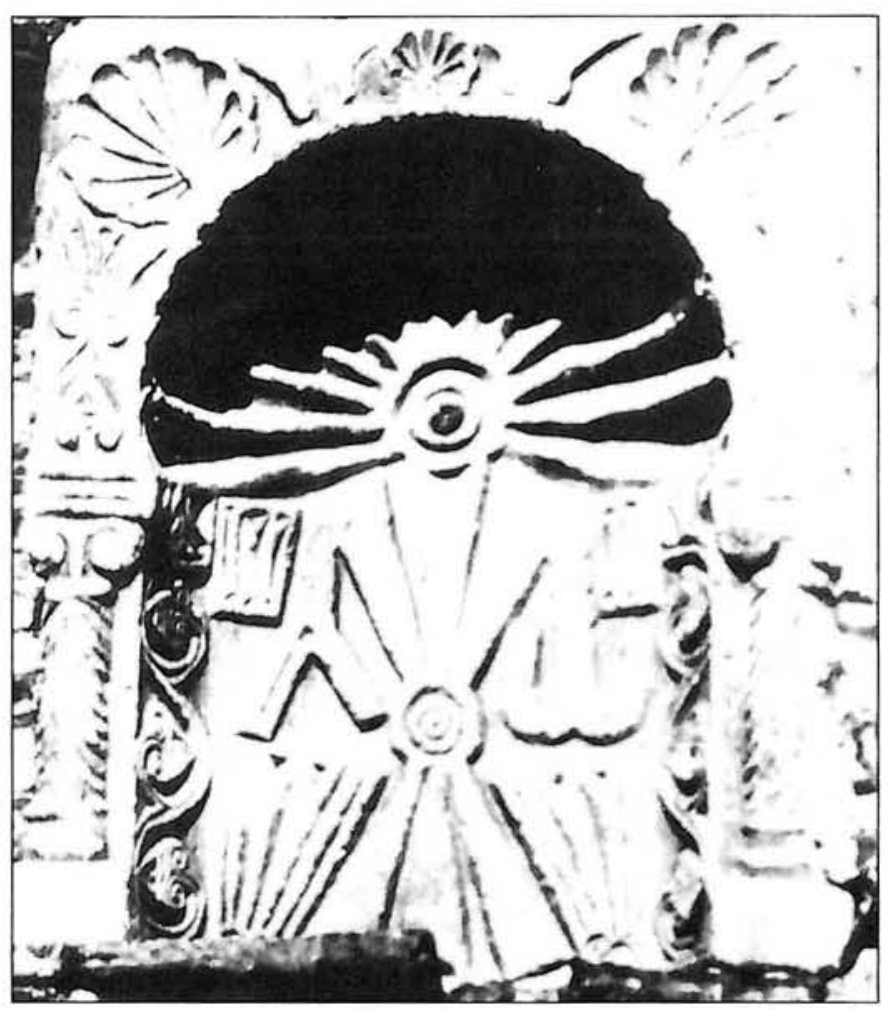

Lámina $\boldsymbol{V}$. Nicho de Santo Tomé (Toledo)

En el caso del nicho de San Pedro Mártir, la decoración lateral que flanquea el crismón está compuesta por tres círculos en relieve con botón central y contornos delineados a bisel, así como segmentos vaciados también mediante corte biselado. Este motivo de círculos secantes en composiciones seriadas es uno de los más abundantemente reproducidos por todos los talleres hispánicos desde la plástica visigoda más temprana, descle los ejemplares de Cabeza de Griego de la primera mitad del siglo vi, hasta algunas representaciones características de las iglesias del siglo VII (basílica palentina de San Juan de Baños). En Toledo, se encuentra plasmado en varias piezas del siglo viı: en un fragmento empotrado en la calle de San Vicente, en un otro conservado en el Museo Arqueológico Nacional y en un ejemplar propiedad del señor Nodal, por citar algunos de los ejemplos más sobresalientes (Znmorano Herrera, 1974, 20-22, figs. 20-22). La repe- 
tición constante en series trinitarias y la sustitución de este motivo por otros alusivos al sacramento eucarístico en el nicho de Santo Tomé, hacen pensar que esta decoración secundaria tuvo en realidad un sentido trascendente y no meramente omamental como en principio pudiera parecer.

En la mayoría de los nichos y placas-nicho es esencial la aparición de dos columnas que actúan como elementos sustentantes de la venera, sirviendo además como marco a la composición. Estas columnas exhiben sus tres partes básicas (basa, fuste y capitel) casi siempre con cierto detalle realista. El tipo de capitel de nuestra pieza está compuesto por dos caulículos de los que brotan dos volutas que rematan junto a los ángulos del ábaco. Este tipo de capitel se encuentra bien documentado en piezas de buito redondo de Mérida y Toledo. Los ejemplares de Mérida se encuadran en el tipo 1 de Cruz Villalón (1985, 178 ss, figs. 68-79, 85-88, 400 y 404)', que es el más numeroso; los del foco toledano, por su parte, pertenecen al sexto grupo de la catalogación de Zamorano Herrera, fechado por esta autora en pleno siglo VI (ZAMORANO HERRERA, 1974, 124-129).

Los fustes de las columnas presentan una amplia morfología: lisos, estriados, estrigilados y en espiguilla. En el caso del nicho de San Pedro Mártir, la columna presenta fuste estriado mediante una fina incisión. Este tipo responde con seguridad a un intento de imitar las grandes piezas decoradas con estrías a bisel de ejemplares de bulto redondo como en las pilastras reutilizadas en el pórtico neogótico de la Alcazaba de Mérida (CRUz VILLALON, 1985, 128-129, figs. 321-324). Las basas de estas columnillas muestran también una morfología variada, alternando escocias y toros. Hay que subrayar la fisonomía particular que adoptan algunos de sus elementos: el desarrollo anormal del plinto que observamos en las columnas de estos ediculos se da igualmente en las pilastrillas descubiertas en Mérida pertenecientes al tipo 1 de Cruz Villalón (1985, 178ss). Schlunk y Hauschild fueron los primeros en observar este fenómeno y lo pusieron en relación con una modalidad de columnitas bastante comunes en la escultura bizantina (SCHLUNK-HaUSCHID, $1978,67)$. En este sentido, Cruz Villalón reparó en que la concentración de hallazgos de este tipo de pilastrillas en tomo a la ciudad de Mérida y en el sur de la Lusitania podrian hacer pensar en la existencia de un prototipo elaborado en la misma capital, aunque con relación directa con los modelos orientales (CRUZ VIIJALON, 1985, 179).

La venera es uno de los elementos más característicos de la serie y en la práctica el que viene a individualizarla. En el caso del nicho de San Pedro Mártir sólo se conserva uno de los gallones de la misma. Desde el punto de vista formal, la venera está relacionada con las estructuras absidiadas de la arquitectura cortesana bajoimperial. Su sentido simbólico se ha mantenido en el arte religioso hasta nuestros días para denotar la idea de veneración heredada del arte y protocolo áulico bajoimperiales (CRUZ VILLALON-CERRILO M. DE CÁCERES, 1988, 187-203). Este concepto vinculado en principio a las formas arquitectónicas pasó pronto a otras realizaciones arísticas, sobre todo a través de las decoraciones de las tapas de encuadernación de los dípticos consulares primero y religiosos después.

${ }^{1}$ Esta autora no se decide a fijar una cronología para este tipo de piezas a partir de los paralelos aducidos, si bien rota el paralelo con capiteies de Rávena catalogados entre los siglos V-IX. 
La elección del nicho como elemento simbólico se hace patente en las más diversas culturas coetáneas para significar el espacio más sagrado de su arquitectura. Así, tanto el aron o armario de la Torab de la sinagoga de Dura Europos (centro del culto hebreo), como los mibrabs de las mezquitas o el baykal de las iglesias coptas (puntos referenciales del culto musulmán y cristiano copto respectivamente) están conformados siguiendo el mismo esquema que los edículos visigodos. Ia intima relación de la venera con la arquitectura se aprecia claramente en los dos únicos casos donde los nichos se han conservado in situ (Vera Cruz de Marmelar y San Pedro de la Nave). En esta ubicación hay que ver también determinados aspectos simbólicos como es la reducción del santuario y su concepción como imagen del nuevo Templo de Salomón, esto es, como símbolo del mismo Cristo. Todo ello iría ligado, a nuestro juicio, con la cada vez mayor influencia que el Apocalipsis de San Juan tuvo en la liturgia y usos religiosos visigodos de la séptima centuria.

El origen y la finalidad de la serie de nichos y placas-nicho continúa siendo un tema debatido entre los distintos investigadores que han abordado el problema. Parece haber acuerdo general, no obstante, en que el nicho constituye el punto focal de la arquitectura religiosa, situándose en un lugar preferente del templo. Existiría entonces en el ámbito mediterráneo un cierto valor simbólico común para piezas como el mibrab islámico o el baykal copto, consecuencia de la expansión de la cultura y de las formas artisticas de origen clásico. Todo ello, por supuesto, con las lógicas variaciones de contenido ideológico que imponen las propias necesidades litúrgicas y de culto.

En el arte visigodo, los nichos se documentan por vez primera en la ciudad de Mérida a finales del siglo Vi. Los ejemplares emeritenses presentan una tipologia muy clasicista, con detalles que indican una inspiración directa en modelos bizantinos, en concreto de algunas piezas escultóricas del taller de Constantinopla fechadas en el siglo iv y de otros testimonios propios de las artes menores como el Evangeliario de Dumbarton (BRANDENBURG, 1972, 143-144 y 153-154, láms. 66-67; SCHLUNK-HAuSCHLD, 1978, 58-59, fig. 37). Piezas como éstas debieron llegar a la peninsula a través de comerciantes de origen oriental (sirios). El ascenso a la sede episcopal emeritense del obispo Paulo, griego de origen, debió estrechar el contacto de la capital lusitana con el oriente bizantino, tal como se trasluce de algunas noticias literarias recogidas en las Vitas Patrum Emeritensium (GARCía MORENO, 1972, 127-154; CAMACHO MACIAS, 1988, 47-57, 93-100 y 101-119).

Desde Mérida, el nicho se difundió hacia el resto de los centros peninsulares, bien hacia el noroeste, a través de Salamanca, o hacia el norte, a partir de la expansión de las formas artisticas toledanas por la Meseta. En cada foco, las formas fueron degenerando paulatinamente sobre modelos locales, con una tendencia común hacia la abstracción y el esquematismo, tal y como se aprecia en la evolución de los ejemplares toledanos. Sólo la placa-nicho hallada en Córdoba parece sustraerse a esta norma, presentando una ejecución más cercana a los prototipos emeritenses, quizá porque en este caso se copió directamente alguna pieza bizantina o un ejemplar basado en ellos (MORIN DE PABLOS, 1994, 65, fig. 18a). No debe olvidarse que las grandes ciudades de la Bética estuvieron en rebelión contra el poder visigodo hasta finales del siglo $\mathrm{vl}$ y que mantuvieron la organiza- 
ción municipal y la ficción imperial hasta fechas muy tardías. En cualquier caso, cabe suponer que los orientales continuaron comerciando directamente con las ciudades del valle del Guadalquivir sin necesidad de la mediación de Mérida, como lo habían hecho en el periodo anterior y como hemos mencionado que sucedia aún en pleno siglo $\mathrm{Lx}^{2}$.

El tema de la funcionalidad de los nichos ha sido, sin duda, el más tratado por la bibliografia. Se han apuntado diversas hipótesis: como credentiae (Amador de los Ríos), como canceles (Camps Cazorla) o como soportes de la mesa de altar (Schlunk), idea seguida por casi todos los autores hasta que Íniguez Almech planteó su situación en el ábside de los templos, en consonancia con la liturgia de la época que establecía que el sacerdote oficiara de espaldas al pueblo. Esta idea parece ser la más plausible, como demuestran las placas-nicho conservados en su emplazamiento original de Vera Cruz de Marmelar y San Pedro de la Nave (AMADOR DE los Rios, 1877, 64; CAMPS CAZORIA, 1985, 483ss y 543; SCHLUNK, 1947, 252; ÍNIGUEZ ALMECH, 1955, 61-62). En opinión de Torres Balbás, esta misma concepción es la que heredaria el mundo islámico y que estaria en la génesis del mibrab, lo que bien pudo suceder a través del contacto directo que el Islam mantuvo con el arte siriaco y copto (TORRES BALBÁS, 1956, 154-156).

En lo que se refiere a la omamentación, los nichos constituyen indudablemente la culminación simbólica de una iconografía religiosa programada hacia la cabecera del templo (el sancta sanctorum), como todavia puede observarse en la iglesia de San Pedro de la Nave. En este sentido, hay que señalar que en una época avanzada del periodo visigodo los altares pasaron a ocupar prácticamente todo el espacio del santuario a medida que éste se reducía como consecuencia de las primeras tentativas de abovedamiento. Es posible, pues, que las mesas de altar apoyaran directamente sobre el muro del testero (asi parece deducirse al menos del estudio de las iglesias de El Gatillo y Santa Lucia del Trampal) haciendo un mismo conjunto con los nichos (CABALlero, 1983, 92-95).

De este grupo habria que exceptuar, sin embargo, el gran nicho de Mérida, cuya morfología parece remitir a su utilización como cátedra episcopal (PUERTAS TRICAS, 1975, 82-83 y 154; CRUZ VILLALON, 1985, 211-214) o, tal vez, como pensamos nosotros, como betoimasia o trono simbólico en el que se depositaban las Escrituras y que espera la Parusía del Señor. En cualquier caso, estas cátedras se hallaban situadas también en el ábside de los templos y no invalida la tesis de que fuera el prototipo de la serie.

Por otra parte, descle un punto de vista ritual es muy probable que los nichos sirvieran como sustitutos simbólicos del ábside y del sancta sanctorum de la iglesia, especialmente durante el desarrollo de determinadas ceremonias litúngicas (NAUTiN, 1967, 37-41). Nos referimos concretamente a la práctica consecratoria del templo realizada por el obispo, quien ungía el crisma sobre determinados puntos rituales de la placa a semejanza de la consagración de la mesa de altar y al rito de recepción del crisma tras la ceremonia bautismal.

${ }^{2}$ Incluso el más crítico de los autores admite la perduración agonica del municipio romano en Andalucia durante el siglo vi (Sánchez Albornoz, 1971, 113). Sobre el senarus cordobés y su impontancia para descifrar los acontecimientos previos a la invasión musulmana véase un interesante estudio de García Moreno (1992, 440-442). 
Todo ello nos lleva a entrar en el significado simbólico de la serie. Algunos autores han defendido la teoría de que los nichos vienen a plasmar la imagen, más o menos idealizada, de la Anastasis construida por Constantino sobre el sepulcro de Cristo en Jerusalén (SALVADOR ORDAX, 1983, 23-38). La idea es sugestiva, pero desde un punto de vista formal sólo parece ser válida para el ejemplar de la Puerta de Alcántara de Toledo y algunas placas relacionadas con ella, como las de Salamanca y Pozoantiguo, en las que se mezcla el origen arquitectónico del modelo (la Anastasis constantiniana) con la tipología propia de los baptisterios, muy influida asimismo por aquél.

El resto del conjunto estaría vinculado, como decimos, a estas especulaciones, si bien de una forma más simbólica. Es posible ver en estos nichos una referencia al arquetipo del Templo de Jerusalén entendido como símbolo del cuerpo de Cristo. Esta interpretación de la serie, basada en la lectura del evangelista San Juan (Jn. II,19-22), remite al pasaje de la resurrección de Cristo y posee además claras connotaciones apocalípticas puestas de manifiesto en la aparición de las letras alfa y omega - símbolos de la divinidad y eternidad de Cristo- y en algunos otros detalles iconográficos (olivos, candeleros) especialmente claros en el caso concreto del gran nicho de Mérida.

Morfológicamente, los nichos muestran una evidente relación formal con la figura del Templo plasmada en otros testimonios materiales. En ellos aparece siempre reducido a sus elementos más característicos, esto es, la fachada y las dos columnas que lo flanqueaban. Esta imagen recuerda, por ejemplo, la esquematización de las representaciones de templos paganos o del mismo Templo de Jerusalén que se observa en numerosas monedas de época clásica, si no fuera porque en nuestra serie el frontón ha sido sustituido por una venera, hecho que habría que poner en relación con un modelo arquitectónico de carácter abovedado.

Esta lectura permitiria dar una explicación convincente no sólo a los ejemplares escultóricos, sino también a todas aquellas piezas fuera de la escultura monumental que presentan idéntica composición iconogräfica (ladrillos estampados de Lebrija y ladrillos

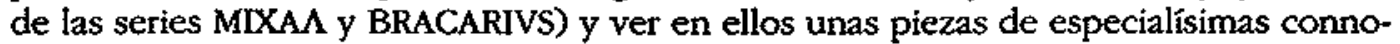
taciones litúrgicas y simbólicas que vinculan los sacramentos del bautismo y la eucaristía a través de la celebración pascual.

\section{CIMACIO}

\section{Dimensiones}

Longitud: $0,26 \mathrm{~m}$; Anchura: $0,15 \mathrm{~m}$; Altura: $0,08 \mathrm{~m}$.

\section{Descripción}

Cimacio tallado en un bloque de mármol blanco (láminas VI y VII). Se encuentra completo, aunque algo desgastado por el roce. La decoración se desarrolla en sus cuatro caras mediante talla biselada, si bien la traza de los motivos se muestra algo irregular entre las distintas caras. 


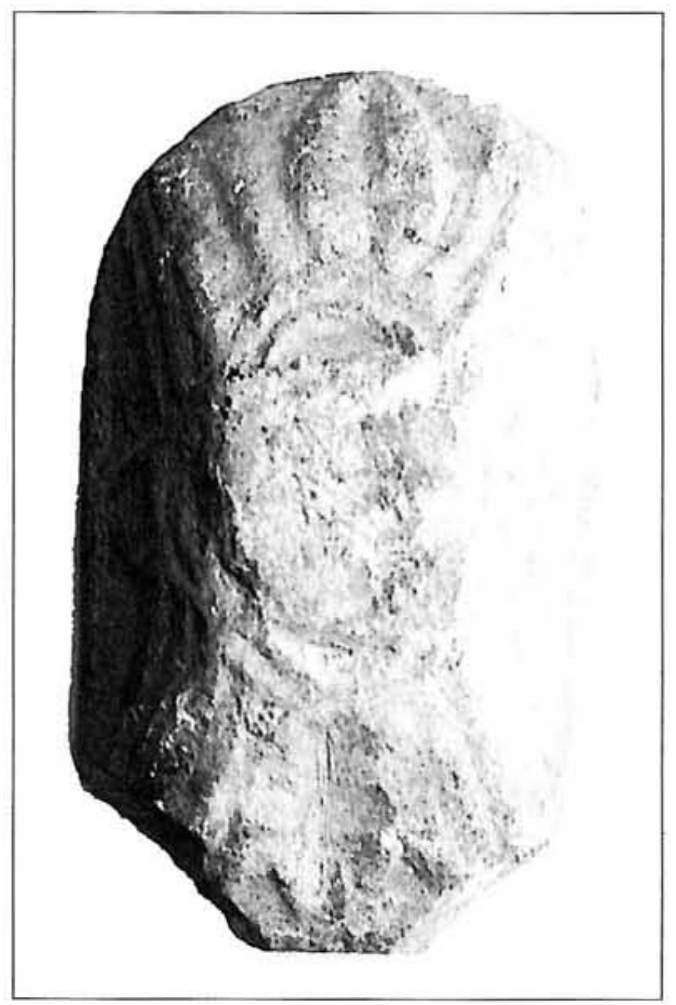

Lämina VI. (imacio).

(ionvento de San Pecles Mártir ('Tolecto)

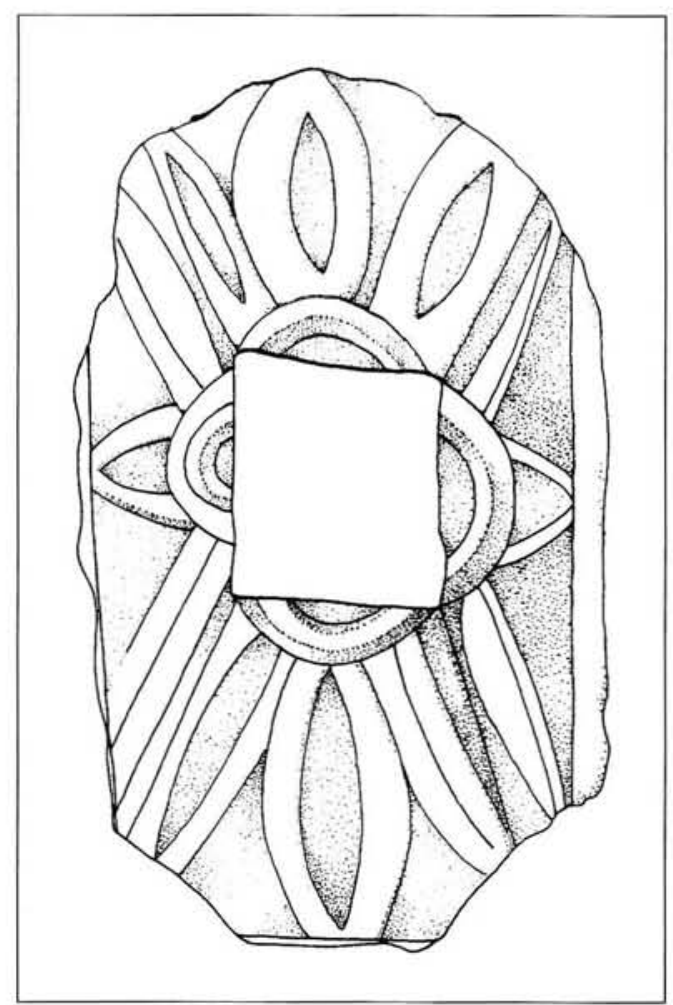

Lämina VII. (Cimacio. (onvento de Sin Peclro Martir (Toledo)

\section{Decoración}

La decoración se compone de trifolias muy esquematizadas que parten de un arco. Las trifolias presentan las hojas apuntadas, siendo las laterales, que ocupan las esquinas del cimacio, algo más alargadas que la central. La factura es algo tosca en líneas generales, con cierta inclinación hacia la clesproporción.

\section{Estudio}

Dentro de la arquitectura hispanovisigoda resulta frecuente la utilización de cimacios, ya que el antiguo sistema constructivo arquitrabado estaba siendo sustituido progresivamente por otro basado en arquerías. Esto conllevaría en la práctica la necesidad de crear una superficie de apoyo más extensa que equilibrase la descarga de los muros sobre los arcos. La innovación del cimacio proviene de la arquitectura bizantina, difuncliéndose rápidamente hacia el mundo occidental. La técnica debió llegar pronto a nuestra península. 
Los tipos de esta serie son sumamente variados. En nuestro caso, parece corresponder a uno de los tamaños más pequeños, tal vez como coronación de una columnita. El ejemplar en cuestión puede englobarse dentro del tipo 1 de Cruz Villalón caracterizado por sus pequeñas dimensiones y su escasa altura. Hay que hacer mención a la evidente desproporción que existe entre la base y la superficie de apoyo, lo que provoca lados muy extendidos y de poca inclinación. La decoración se inscribe dentro de este marco arquitectónico, razón por la que aparece simplificada en extremo (CRUZ VILIALON, 1985, 240-241).

En Toledo, el cimacio constituye una de las piezas más características de su rica serie escultórica. Su origen hay que ponerlo en relación con los ejemplares emeritenses, aunque se observa de nuevo una tendencia a la simplificación morfológica y, en lo ornamental, hacia la abstracción geométrica. Los paralelos más cercanos del ejemplar de San Pedro Mártir se encuentran en los cimacios toledanos de la Vega Baja, de San Pablo de Montes y en dos piezas conservadas en el Museo de Santa Cruz, todos ellos encuadrados cronológicamente dentro de la séptima centuria (ZAMORANO HERRERA, 1974, 134138 , figs. $48-49$ y $119-120$ ).

Sobre el tema decorativo de la trifolia sobre semicírculo, debemos señalar tan sólo que es uno de los motivos más frecuentemente representado en la plástica visigoda, tanto en composiciones continuas como de forma aislada. La aparición de la trifolia señalada flanqueando la cruz en no pocas ocasiones, o bajo marco avenerado en otras, indica que este motivo tuvo un sentido trascendente más allá de lo puramente ornamental. Como prueba de lo dicho puede aducirse un conocido pilar de ensamblaje de Mérida con decoración de trifolia bajo venera (CRUZ VLLALÓN, 1985, 53, fig. 28). Se ha señalado que la trifolia es una esquematización del tema del árbol de la vida, algo que se puede ver bien en algunas representaciones de palmeras como las que decoran los frisos exteriores de Quintanilla de las Viñas. Esto puede apreciarse también en que se trata de uno de los escasos motivos que aparece cobijado bajo venera, junto a crismones, árboles de la vida en todas sus variantes y menorot. Junto a ello, hay que citar también un fenómeno que se viene desarrollando desde finales del siglo vi en la escultura arquitectónica: nos referimos a la cristianización de los elementos arquitectónicos. A partir de esta fecha, columnas, capiteles y cimacios aparecen decorados con diversos símbolos religiosos. Resulta interesante comparar ciertos capiteles de similar factura que sustituyen o alternan el signo de la cruz y la trifolia (p.e. en los capiteles de San Juan de Baños). Todo ello no hace sino confirmar el carácter simbólico que debió de tener este motivo vegetal, carácter que cabe imaginar para la repetición en series triples del mismo o duplicadas flanqueando una cruz, tan abundantes en la escultura visigoda del siglo viI.

\section{FRISO}

\section{Dimensiones}

Longitud: $38 \mathrm{~cm}$; Anchura: $16 \mathrm{~cm}$ (real); Grosor: $8 \mathrm{~cm}$. 


\section{Descripción}

Friso decorado con círculos imbricados formando terrafolias enmarcadas por un sencillo listel (láminas VIII y IX). El estado de conservación de la pieza es muy deficiente: aparece fragmentado en todos sus lados y con la decoración muy gastada. La talla acusa un fuerte trabajo a bisel; los laterales, por el contrario, se encuentran cincelados.

\section{Decoración}

La omamentación de este friso presenta una serie de círculos secantes de idéntico diámetro formando rosetas tetrapétalas. Ya hemos comentado algo anteriormente sobre este diseño, frecuentísimo en el arte toledano, al hablar de la decoración lateral del nicho. Su procedencia parece estar en algunas realizaciones norteafricanas de temática cristiana, caracterizadas por una fuerte tendencia hacia la geometrización y que bien pudieron llegar hasta Toledo a través de Mérida o de la Bética. En cualquier caso, el motivo de los círculos secantes es habitual dentro del arte musivario romano y se perpetúa en el mundo bizantino. En última instancia, es en los cartones musivos romanos de tema a compás donde habría que buscar el origen de la composición.

En la escultura toledana de la séptima centuria el tema de los círculos secantes aparece abundantemente representado en sus formas más variadas. La que aquí nos ocupa es la más sencilla, sin que ello signifique indicio de una cronologia anterior. Como ejemplos significativos dentro del arte toledano tenemos el fragmento empotrado en el callejón de San Ginés y el friso reutilizado en la fábrica de la torre de Santa Eulalia (Zamorano Herrera, 1974, 46-49, figs. 16-17). La difusión del motivo desde Mérida está atestiguada en varios hallazgos de la Meseta norte, como demuestra un friso de extraordinaria calidad hallado en la población salmantina de La Tala (BARkOSO-MORIN, 1992, 65-66, fig. 14, lám. VII-X) que, sin duda, hay que poner en relación con la producción de algún taller emeritense. Posteriormente, desde Toledo el motivo se difundió también hacia otros centros peninsulares ligados a la acción real. Así, por ejemplo, el tema aparece tallado en las impostas de arranque de la bóveda de la capilla mayor de la iglesia palentina de San Juan de Baños (PALOL, 1988, 53), obra debida a la labor de artesanos toledanos vinculados a la corte de Recesvinto.

\section{Estudio}

Llama la atención, en primer lugar, la práctica ausencia de frisos decorativos en la escultura emeritense que pudieran parangonarse con los ejemplares toledanos. Esta escasez (tan sólo se conoce una pieza emeritense identificable con seguridad como friso) parece indicar de una manera clara que las iglesias de Mérida de cronología temprana debieron de contar con un sistema ornamental muy diferente de lo que conocemos para la arquitectura toledana de la séptima centuria. En realidad, las basílicas emeritenses del siglo vi continuarían probablemente la práctica arquitectónica y decorativa fijada en 
época paleocristiana, con abandono de ciertas técnicas ornamentales propias de este arte (mosaicos, pinturas, etc.) para centrarse en la escultura. No se olvide tampoco que la capital lusitana debió contar con importantes templos erigidos en el siglo v que todavía permanecerían en pie una centuria más tarde cuando fueron parcialmente remodelados.

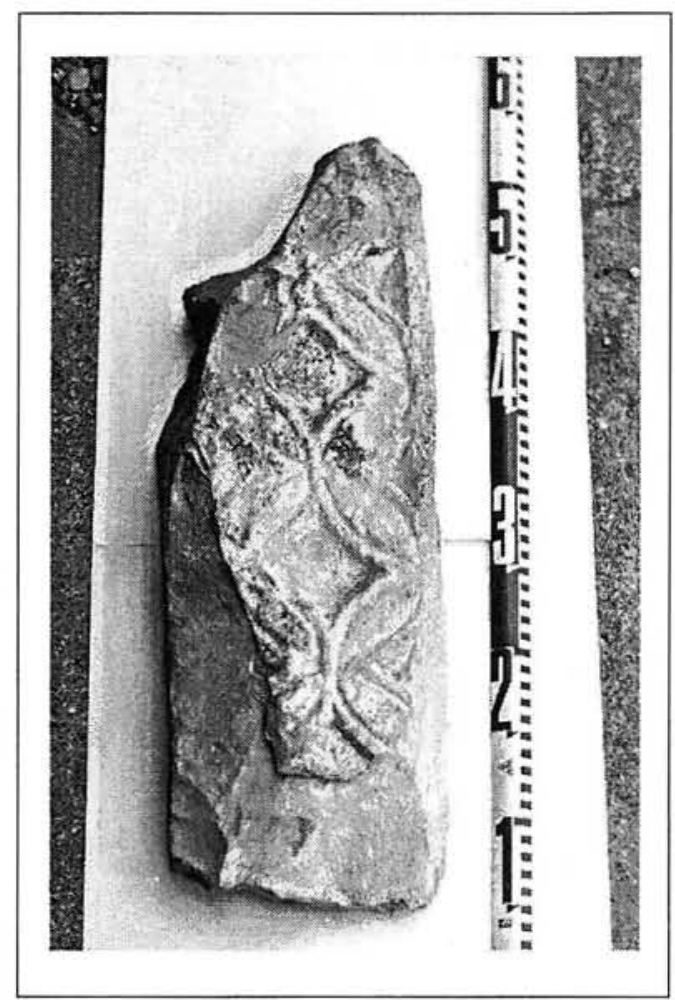

Lámina VIII. Friso.

Convento de San Pedro Mártir (Toledo)

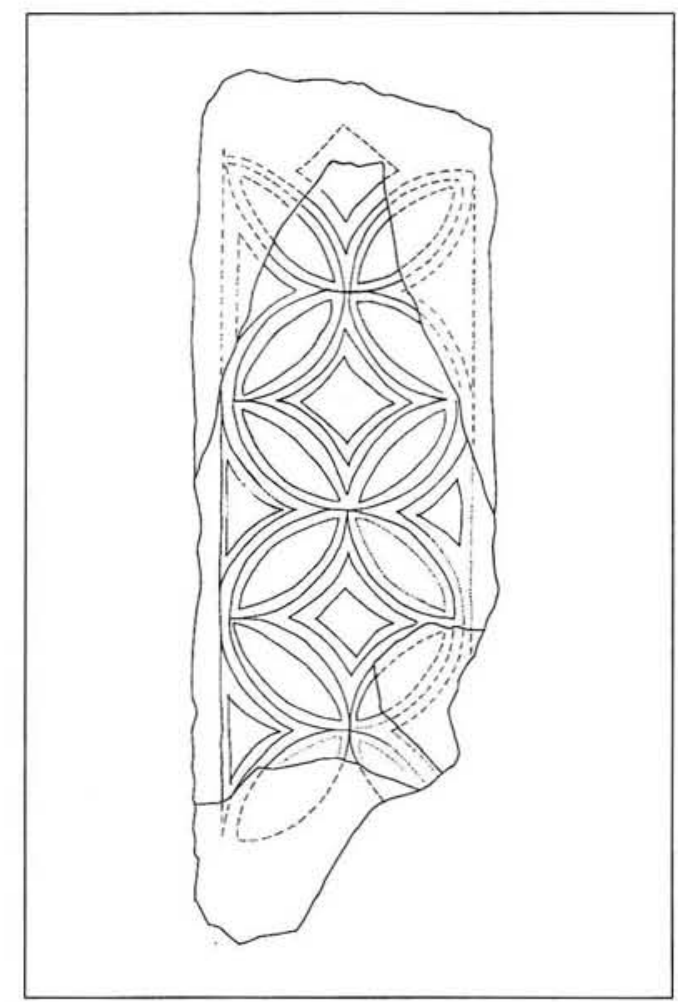

Lâmina IX. Nicho.

Convento de San Pedro Mártir (Toledo)

Hacia el siglo VII, se observa un importante cambio en la decoración y en la estructura de los edificios hispánicos. A partir de ese momento, el arte visigodo elaborado en Toledo desarrolla un tipo de decoración en el que los frisos adquieren paulatinamente un mayor protagonismo, pasando a ornamentar los paramentos interiores y exteriores de las construcciones. La importancia de los frisos estriba probablemente en el abovedamiento de las estructuras y en la práctica de una arquitectura basada sobre todo en la solidez de los paramentos. De esta forma, los frisos vienen a decorar los arranques de las bóvedas y su utilización en la decoración de los muros se explica como un intento de romper la monotonía que produce la sucesión de paramentos lisos, adquiriendo en ocasiones un sentido simbólico muy concreto. 
El desarrollo de unas formas arquitectónicas complejas y fuertemente jerarquizadas a lo largo del siglo vil debió de influir también en el gusto por estas piezas que, en cualquier caso, venían además a subrayar además la importancia del presbiterio y de ciertas partes esenciales del edificio, tales como puertas o ventanas. De este modo, la decoración a base de fajas decoradas con relieves marcaba el recorrido hacia el santuario del templo, en un camino ascensional que no queda más remedio que poner en relación con la celebración del misterio eucarístico y, por consiguiente, con el altar. Quizás sea en los frísos exteriores de Quintanilla de las Viñas y en los que decoran el santuario de San Pedro de la Nave donde mejor se aprecie esta iconografía programada hacia el santuario.

\section{CONCLUSIONES}

Parece deducirse, pues, a tenor de lo dicho anteriormente, que las tres piezas aquí estudiadas debieron pertenecer probablemente a un mismo edificio que reúne las características propias de la arquitectura del siglo vil: concentración de la decoración hacia un punto focal situado en el ábside y ocupado por un nicho, utilización de frisos decorativos, así como esquematización de los motivos ornamentales con cierta tendencia hacia formas geometrizantes (trifolias, círculos secantes, etc.).

Un problema aparte es la adscripción de estos restos a un edificio preciso de los que dan noticia las fuentes de la época. Aunque la capitalidad de Toledo puede retrotraerse hasta tiempos de Teudis, no parece ser hasta el reinado de Leovigildo cuando la ciudad del Tajo adquiera realmente rango de urbs regia. A partir de este momento, se aprecia un auge en la edilicia de la urbe vinculado no sólo a la importancia de su sede episcopal, sino a la creciente política centralizadora seguida por los monarcas toledanos de finales del siglo vi y primera mitad de la centuria siguiente.

El emplazamiento de esta arquitectura nos es parcialmente conocido gracias a las fuentes literarias pero, a diferencia de Mérida, donde contamos con un testimonio excepcional como son las Vitas, en Toledo necesitamos recurrir en no pocas ocasiones a fuentes tardías y muy adulteradas como son los cronicones medievales.

Entre los pocos datos incuestionables, sabemos que en el interior de la ciudad se hallaba la iglesia de Santa Maria, que recibe diversas denominaciones (basilica, sedes, ecclesia) y donde se celebraron los Concilios IX (noviembre del año 655) y XI (año 675) bajo los reinados de Recesvinto y Wamba respectivamente. Esto podría ser indicativo de una fecha tardia para esta iglesia o mejor una remodelación de la misma por esta época, dentro ya de la segunda mitad del siglo vil. Amador de los Ríos sitúa este templo en el lugar que ocupó antiguamente el Convento del Carmen Calzado. Garcia Rodriguez, sin embargo, piensa que la advocación a la Virgen se reservaba exclusivamente a la catedral y, por tanto, sus restos se hallarían bajo la actual sede primada (GARCía RoDRíGUEZ, 1966, 127). En este sentido, Camps Cazorla parece identificar la catedral toledana con la iglesia denominada Santa María in Sorbaces a la que un tal Sonnica (quizá un alto dignatario godo) ofreció una cruz (VIVES, n. ${ }^{\circ}$ 377; CAMPS CAZORIA, 1985, 558-559, nt. 55-56; STORCH 
DE GRACla, 1990, 564). Puertas Tricas opina que esta afirmación es gratuita (PUERTAS TRICAS, 1975, 30).

Mayores problemas presenta el emplazamiento de las iglesias de San Sebastián y de San Ginés. La tradición supone que la primera de ellas fue construida durante el reinado de Liuva II en el año 601 en la parte meridional de la ciudad, junto al río Tajo. En ambos casos su pretendido visigotismo se apoya en un epigrama atribuido erróneamente a San Ildefonso. Aunque realmente no existen datos literarios que permitan identificarlas, lo cierto es que en la zona en cuestión se han documentado diversos restos escultóricos de época visigoda (AMADOR DE los Ríos, 1905, 38; PUERTAS TRICAS, 1975, 34).

La iglesia de Santa Justa, atribuida a tiempos de Atanagildo, no aparece mencionada en las fuentes literarias visigodas, aunque Amador de los Ríos la identifica con una iglesia mózarabe posterior. Según testimonio del mismo autor, allí se conservaban en su época varias pilastras visigodas. En opinión de Puertas Tricas, no hay motivo para pensar que estas tres iglesias se remonten al periodo visigodo si se exceptúa el testimonio de Amador de los Ríos (AMAdOR De los Ríos, 1905, 38; PUERTAS TriCAS, 1975, 34).

La tradición refiere que la iglesia de Santa Eulalia es una fundación de Atanagildo. En realidad, esta iglesia conserva una serie de capiteles visigodos que se encuentran reutilizados dentro de la construcción actual. Storch de Gracia cree que este templo tendría adosado el monasterio homónimo cuyo abad firmó las actas del XI Concilio de Toledo (año 675) (STORCH DE GRACIA, 1990, 556). La advocación a Santa Eulalia podría indicar una datación temprana para esta iglesia, quizás de mediados del siglo vi o comienzos del siglo VII, paralela asi a la refacción de la basilica emeritense dedicada a la mártir realizada por el obispo Fidel.

Es posible que en el interior de la ciudad se encontrara también la iglesia de San Miguel aneja al monasterio del mismo nombre y cuyo abad firmó el XI Concilio de Toledo celebrado en el año 675 ("Julianus, ecclesiae monasterii sancti Michaelis abba"). El templo se asocia a la actual iglesia de San Miguel el Alto en cuyas inmediaciones se han documentado restos escultóricos de época visigoda (STORCH DE GRACIA, 1990, 556). Las actas conciliares no dicen expresamente que este monasterio estuviera ubicado en la misma capital pero es una posibilidad a tener en cuenta. En realidad, parece haber sido habitual la existencia de monasterios con todas sus dependencias en el interior de los centros urbanos de cierta importancia, a pesar de la amonestación de la regla isidoriana contraria a esta práctica: "uillam sane longe remotam esse oportet a monasterio ne uicinius posita aut laborem ferat periculi aut famam inficiat dignitatis." (Reg. Isid. De monasterio, 1,22-23; García Moreno, 1977-78, 317).

Extramuros de la ciudad, situadas en distintos puntos de sus suburbia, se levantaban numerosas iglesias de las que tenemos testimonio cumplido gracias a las fuentes literarias. Entre ellas destaca la iglesia dedicada a Santa Leocadia construida en tiempos de Sisebuto: "Toleto quoque beatae Leocadiae aula miro opere... culmine alto extenditur" (Vitas $I V, 6,7)$. Junto a ella, el templo más importante era la iglesia de los Santos Apóstoles Pedro y Pablo citada en la documentación de la época como basilica praetoriensis. Esta denominación indica la especial relación que dicha basilica mantenía con el palacio 
real, sede de la guardia real. En esta iglesia tenía lugar la ceremonia de entrega de la reliquia de la Vera Cruz al monarca para ser utilizada como estandarte en las campañas militares (Ordo quando rex cum exercitu ad prelium egreditur) (FÉROTIN, 1904, col. 149153; SCHLUNK, 1985, 10).

Se conoce igualmente la existencia de un templo dedicado al culto de la Santa Cruz por las actas del XI Concilio de Toledo (año 675). Se trataba de una iglesia monástica, como prueba el hecho de que Absalio en dicho sínodo firme como "ecclesiae monasterii Sanctae Crucis abba" (VIVES, 1963, 369). A dicha iglesia se dirigia el Viernes Santo una procesión que partía de la catedral y que conducía una reliquia de la Vera Cruz (FÉrotin, 1904, xxii, col. 193-204; SCHLUNK; 1985, 9-10). Hay noticias de otros monasterios situados también en el área suburbana de la capital, algunos de ellos pudieron ser los ya citados de Santa Eulalia, San Miguel y Santa Cruz a los que nos hemos referido anteriormente como cenobios intramuros. En cualquier caso, habria que sumar además el importante monasterio agaliense, centro monástico en el que se formaron las principales figuras del episcopado toledano. Este cenobio, advocado al culto de San Julián y Santa Basilisa, se encontraba situado en las afueras de la urbs regia, "in suburbio toletano" (PUERTAS TRICAS, 1975, 32-33; STORCH DE GRACIA, 1990, 568-569; OLMO ENCISO, 1987, 348).

A pesar de estos datos documentales, apenas se puede conocer algo de la topografía antigua de Toledo. Es posible, sin embargo, establecer unos parámetros generales conjugando lo que es habitual en otras ciudades de la época y las escasas noticias literarias. Como ha observado el profesor Palol, la civitas regia toletana debió tener tres importantes centros de culto dependientes de las jerarquías políticas y religiosas: una iglesia catedral, muy posiblemente dedicada a la Virgen María, sobre todo a partir del Concilio de Éfeso (año 431) en el que se fija definitivamente el dogma de la Theotokos. Esta iglesia catedralicia suele estar asociada tanto al palacio episcopal como a un centro bautismal advocado al Bautista. En segundo lugar, tendríamos un templo áulico situado junto a la residencia real y que en Toledo parece tener fuertes connotaciones militares. Como ya se ha comentado, dicha iglesia estaba advocada a los Santos Apóstoles Pedro y Pablo, y en tiempos de Wamba llegó a constituir la sede de un efímero obispado castrense con el que el monarca se proponía mermar la autoridad del obispo toledano (García Villada, 1932, II, 1. ${ }^{2}, 98$; Palol, 1991, 790). En este templo tuvieron lugar las unciones reales de Wamba (a. 672) y Egica (a. 687). Por último, la ciudad contaba con un templo de carácter martirial o memoria dedicado a Santa Leocadia de cuya fundación en el año 618 se tiene noticia gracias al Apologeticus de San Eulogio: "... tempore Heraclii imperatoris anno imperil eius septimo, currente era DCLVI. Toleto quoque beatae Leocadiae aula miro opere, iubente praedicto Principe culmine alto extenditur" (PALOL, 1991, 788-791).

Casi todos los autores insisten en situar la antigua cátedra visigoda bajo la fábrica de la actual sede catedralicia. Palol llega a pensar incluso que este centro se remontaría al siglo $\mathrm{V}$, tras las últimas disposiciones teodosianas que determinan el cierre de los ternplos paganos (PAlOL, 1991, 789). Así, una inscripción dedicada a una iglesia de Santa María fechada en el reinado de Recaredo y aparecida en Toledo a finales del siglo xv 
(VIVES, 1969, 100, n. $\left.{ }^{\circ} 302\right)^{3}$ es interpretada por este autor como una consagración in catolico de un templo arriano o apropiado por el arrianismo oficial. Como señala el mismo profesor Palol, es importante subrayar este aspecto de la advocación a Santa María en un momento en que en Bizancio el culto a la Theotokos llega a tener una evidente lectura política, como protectora del Estado y de un sistema de gobierno fuertemente imbuido de ideas teocráticas (PALOL, 1991, 789).

Este conjunto catedralicio compuesto por iglesia catedral y palacio episcopal lievaría asociado un complejo bautismal como sabemos que sucedía en la misma Mérida. Palol señala la existencia desde el siglo xil de la iglesia de San Juan del Arzobispo en las inmediaciones de la actual calle de la Trinidad (PALOL., 1991, 789). Hay que subrayar la cercanía de esta manzana al lugar donde ha sido hallada precisamente la placa-nicho de San Pedro Mártir. Es sugestivo pensar que esta placa decorase el antiguo complejo bautismal. La iconografia de la pieza, especialmente la inversión de las letras apocalípticas puede tener, como se ha dicho ya, una lectura eminentemente bautismal como simbolo del paso del neófito a la vida de la gracia que proporciona el sacramento iniciático.

En este hipotético caso, la aparición de esta serie de elementos decorativos propios de la arquitectura de la séptima centuria podría ser indicativo de una reforma del antiguo complejo paleocristiano que se supone situado en el solar anexo a San Pedro Mártir. Remodelaciones urbanísticas de importancia en la ciudad de Toledo sabemos que tuvieron lugar bajo los reinados de Leovigildo-Recaredo y, posteriormente, en tiempos de Wamba. De la labor de renovación urbanistica de este último monarca da noticia la Continuatio Hispana, según la cual durante su reinado se invocó el patrocinio de los mártires toledanos para la ciudad y sus habitantes (TORRES LOPEZ, 1985, 126). Esta acción recuerda el ejemplo de otras ciudades orientales como Edesa o la propia Constantinopla, y debió ir ligada a la amplia difusión que el culto a las reliquias experimentó en los años finales del reino visigodo. En este contexto podría explicarse la tradición recogida en el siglo xvi por Pedro Fernández del Pulgar que relaciona la construcción de la cripta de la catedral de Palencia con la traslación desde Septimania de los restos de San Antolín precisamente durante el reinado de Wamba.

Sin duda, en el fondo de estas remodelaciones subyace el deseo de dotar a Toledo de una arquitectura acorde con su nuevo papel de capital del reino a imitación de lo que sucedía en Constantinopla, el modelo más próximo y el que debió influir con más fuerza en la mente de los monarcas visigodos. No es extraño, por tanto, que la documentación de la séptima centuria titule con frecuencia a la ciudad como urbe regia. La reforma del antiguo complejo bautismal debió venir provocada además por la necesaria adaptación a los nuevos usos litúrgicos que implicaba el paso del rito de inmersión en piscina bautismal al uso más frecuente de vasos o pilas bautismales conforme el bautismo de adultos dejaba paso al de infantes.

Con todo, la topografia del antiguo Toledo visigodo sigue siendo, en el estado actual de las investigaciones, una grave incógnita, quizá la más relevante de la arqueología

${ }^{3}$ La inscripción fue encontrada en el año 1591 junto al convento de San Juan de la Penitencia. 
de la época. Es indudable que resulta indispensable continuar ahondando en el trabajo arqueológico en busca de estructuras arquitectónicas que permitan corroborar o desechar definitivamente nuestra visión actual de la antigua urbs regia, pero, sobre todo, que permitan clarificar algo más nuestro conocimiento de lo que fue el último arte de la romanidad tardía en la Península.

\section{BIBLIOGRAFIA}

ALMEIDA, F. de, y BORGES, E. (1965): "Igreja visigotica de São Gião. Campanha de escavaçōes durante agosto de $1965^{\circ}$. IX Congreso Nacional de Arqueología. Valladolid. 405-407.

ALONSO SÁNCHEZ, M. A. (1983): "Crismones omega-alfa en España", II Reunió d'Archeologia Paleocristiana Hispànica. Barcelona, 297-302.

- (1989): "Pilas bautismales sorianas con omega-alfa". II Symposium de Arqueología Soriana, t. II. Soria, 1131-1142.

AMADOR DE LOS Rfos, A. (1877): "Monumentos latino-bizantinos de Mérida". Monumentos arquitectónicos de España. Madrid.

AMADOR DE lOS Rf́os, A., y VILLALTA, R. (1905): Monumentos arquitectónicos de España. Toledo. Madrid.

BANK, A. (1977): L'art byzantine dans les musées de l'Union Soviétique. Leningrado.

Barroso Cabrera, R., y Morin de PABlos, J. (1992): "La escultura de época visigoda en la provincia de Salamanca". Salamanca. Revista de Estudios 29-30. 41-73.

- (1995): "El relieve de Montánchez. Iconografia y pensamiento cristiano en el arte de época visigoda". Almud 6 (jul.-sept.), 1-80.

BRANDENBURG, H. (1972): "Ein frühchristliches Relief in Berlin". Mitteilunge des Römischen Instituts 79. 123-154; Tf. 66-80.

CABAllero ZOREDA, L. (1987): "Hacia una propuesta tipológica de los elementos de la arquitectura de culto cristiano de época visigoda (Nuevas iglesias de El Gatillo y El Trampal)". II Congreso de Arqueologia Medieval Española, t. I. Madrid. 61-98.

CAMACHO MActas, A. (1988): El libro de las Vidas de los Santos Padres de Mérida. Madrid.

CAMPS CAZORLA, E. (1985 ( $5 .{ }^{2}$ ed.)): "El arte hispanovisigodo". Historia de España de Menéndez Pidal, t. III. Madrid. 493-668.

CERRILIO M. DE CÁCERES, E. (1972-73): "Cancel de época visigoda de Montánchez". Zephyrus XXIII-XXIV, 261-268.

- (1974): "Los relieves de época visigoda decorados con grandes crismones". Zephyrus XXV, 439-457.

- (1979): "Iconografia del relieve de Montánchez. Acerca de un programa decorativo en las iglesias del siglo vi". Estudios dedicados a C. Callejo Serrano. Cáceres. 
CRUZ VILLALON, M. (1985): Mêrida visigoda. La escultura arquitectónica y litúrgica. Badajoz.

CRUZ VILLALÓN, M., y CERRLLIO M. DE CÁCERES, E. (1988): "La iconografia arquitectónica desde la Antigüedad a la época visigoda: ábsides, nichos, veneras y arcos". Anas I, 187-203.

FÉROTIN, M. (1904): Le Liber Ordinum en usage dans l'Eglise wisigotbique et mozarabe d'Espagne, du V au XF siècle. Paris.

FerRuA, A. (1991): La polemica antiarriana nei monumenti paleocristiani. Ciudad del Vaticano.

Franco MATA, A. (1982): "Un crismón ravenático en Toledo". Boletin de la Real Academia de Bellas Artes y Ciencias de Toledo LXVI, 289-298.

Garcfa MORENo, L. A. (1972): "Colonias de comerciantes orientales en la Península Ibérica. Siglos V-VII". Habis 3, 127-154.

- (1977-78): "La cristianización de la topografía de las ciudades de la Peninsula Ibérica en la Antigüedad tardía". Archivo Español de Arqueología 50-51. 311-321.

- (1992): "Los últimos tiempos del reino visigodo". Boletín de la Real Academia de la Historia CLXXXIX, cuad. 3 (sept.-dic.). 423-459.

GARCIA RODRfGUEZ, C. (1966): El culto a los santos en la España romana y visigoda. Madrid.

GARCIA DE VILLADA, Z. (1932): Historia eclesiástica de España. Madrid.

GIORDANI, R. (1978): "Probabili echi della crisi arriana in alcune figurazioni paleocristiane". Rivista di Arcbeologia Cristiana, anno LIV, n. 3-4, 229-263.

GuARDUCCI, M. (1958): I graffiti sotto la confessione di San Pietro in Vaticano. Roma.

- (1959): La tomba di Pietro. Notizie antiche e nuove scoperte. Roma.

INIIGUEZ ALMECH, F. (1955): "Algunos problemas de las viejas iglesias españolas". Cuadernos de trabajo de la Escuela Española de Historia y Arqueologia en Roma, t. VII. Madrid-Roma. 7-182.

MORIN DE PABLOS, J. (1994): Estudio bistónico-arqueológico de los nichos y placas-nicho de época visigoda en la Peninsula Ibérica: Origen, funcionalidad e iconografía. Universidad Autónoma de Madrid. Memoria de Licenciatura (inédita).

Nautin, P. (1967): "La conversion du temple de Phiale en église chrétienne". Cabiers Archéologiques XVII, 1-44.

OLMO ENCISO, L. (1987): "Los conjuntos palatinos en el contexto de la topografía urbana altomedieval de la Península Ibérica". II Congreso de Arqueología Medieval Española, t. II. Madrid. 345-352.

Palol y Salellas, P. de (1950): "Escultura de época hispanovisigoda en Gerona". Analecta Sacra Tarraconensia vol. XXIII, fasc. 1. 1-14.

- (1988): La basilica de San Juan de Baños. Palencia. 
- (1991): "Resultados de las excavaciones junto al Cristo de la Vega, supuesta basílica conciliar de Santa Leocadia, de Toledo. Algunas notas de topografia religiosa de la ciudad". El Concilio III de Toledo. XIV Centenario 1589-1989. Toledo. 787-801.

PUERTAS TRICAS, R. (1975): Iglesias hispánicas (siglos IV-VII). Testimonios literarios. Madrid.

SALVADOR ORDAX, A. (1983): "Simbolismo en la escultura altomedieval: la Anástasis y los relieves hispanovisigodos de nichos y placas-nicho". VII Congreso de Estudios EXtremeños. Badajoz, 23-38.

SÁNCHEZ-ALBORNOZ, C. (1971): "Ruina y extinción del municipio romano en España e instituciones que le reemplazan". Estudios visigóticos. Cuadernos del Instituto Jurídico Español. Roma.

SCHLUNK, H. (1947): Arte visigodo. Ars Hispaniae, t. II. Madrid.

- (1985): Las cruces de Oviedo. El culto de la Vera Cruz en el reino asturiano. Oviedo.

SCHLUNK, H., y HaUSCHLD, Th. (1978): Die Denkmäler der frühchristlichen und westgotischen Zeit. Hispania Antiqua. Mainz am Rhein.

STORCH DE GRACIA Y ASENSIO, J. J. (1990): "Las iglesias visigodas de Toledo". I Congreso de Arqueologia de la provincia de Toledo. Toledo.

TORRES BALBAS, L. (1956): "Nichos y arcos lobulados". Al-Andalus XXI, fasc. 1. 127-144.

TORRES LOPEZ, M. (1985 (5. ed.)): Las invasiones y los reinos germánicos de España. Años 409-711. Historia de España de Menéndez Pidal, t. III. Madrid. 3-142.

VIVES GATELL, J. (1963): Concilios visigóticos e bispanorromanos. Barcelona-Madrid.

- (1969): Inscripciones cristianas de la España romana y visigoda. Monumenta Hispania Sacra II. Barcelona-Madrid.

- (1969): Inscripciones cristianas de la España romana y visigoda. Barcelona ( $2 .^{2}$ ed.).

WeitzmanN, K. (ed.) (1978): Age of Spirituality. Late Antique and Early Christian Art. Third to Seventb Century. Nueva York.

Zamorano Herrera, I. (1974): "Caracteres del arte visigodo de Toledo." Anales Toledanos X. 7-149. 